\title{
Endocrine and metabolic emergencies in children: hypocalcemia, hypoglycemia, adrenal insufficiency, and metabolic acidosis including diabetic ketoacidosis
}

\author{
Se Young Kim, MD, PhD \\ Department of Pediatrics, Bundang \\ Jeseang General Hospital, Daejin \\ Medical Center, Seongnam, Korea
}

Received: 9 December, 2015 Accepted: 21 December, 2015

Address for correspondence: Se Young Kim, MD, PhD

Department of Pediatrics, Bundang Jeseang General Hospital, Daejin Medical Center, 20 Seohyeonro 180beon-gil, Bundang-gu, Seongnam 13590, Korea Tel: +82-31-779-0273

Fax: +82-31-779-0894

E-mail: odajulia@dmc.or.kr
It is important to fast diagnosis and management of the pediatric patients of the endocrine metabolic emergencies because the signs and symptoms of these disorders are nonspecific. Delayed diagnosis and treatment may lead to serious consequences of the pediatric patients, for example, cerebral dysfunction leading to coma or death of the patients with hypoglycemia, hypocalcemia, adrenal insufficiency, or diabetic ketoacidosis. The index of suspicion of the endocrine metabolic emergencies should be preceded prior to the starting nonspecific treatment. Importantly, proper diagnosis depends on the collection of blood and urine specimen before nonspecific therapy (intravenous hydration, electrolytes, glucose or calcium injection). At the same time, the taking of precise history and searching for pathognomonic physical findings should be performed. This review was described for fast diagnosis and proper management of hypoglycemic emergencies, hypocalcemia, adrenal insufficiency, and metabolic acidosis including diabetic ketoacidosis.

Keywords: Hypoglycemia, Hypocalcemia, Adrenal insufficiency, Metabolic acidosis, Diabetic ketoacidosis

\section{Introduction}

Because the symptoms and signs are nonspecific, this may lead to a missed diagnosis and serious consequences. Fast diagnosis can be possible by index of suspicion and collection of initial laboratory specimens, which could lead to rapid gain of results about patient status and prompt treatment.

\section{Symptoms and signs}

The initial presentations of children with endocrine disturbances are not different to other emergencies, especially newborn babies and infants, such as sepsis, meningoencephalitis, and intoxication. The degrees of altered consciousness range from mild drowsiness to complete obtundation. Signs related to central nervous system (CNS) impairment are lethargy, irritability, tremor, coma, seizure, and Cheyne-Stokes (irregular, shallow) respirations. Those related to metabolic acidosis are nausea, vomiting, poor feeding, weight loss, failure to thrive and Kussmaul (rapid, deep) respirations. The changes in muscle tone such as hypotonia are common. The signs of cardiovascular effects are tachycardia, hypotension, and shock. 


\section{Sampling blood and urine before treatment}

Appropriate simultaneous sampling of initial and archival specimen is very important to assess endocrine metabolic emergencies before nonspecific treatment (intravenous glucose, hydration and electrolytes). Archival samples are obtained at the same time as the initial samples and are held in the laboratory for future measurement. The initial and archival samples of blood and urine are collected, as soon as possible, after the patient arrives in the emergency department or intensive care unit. Serum electrolytes, glucose, blood gas analysis, ammonia, calcium, magnesium, phosphorus, osmolality, bicarbonate, liver function tests, and urine electrolytes/osmolality are usually assessed with initial sample. The calculation of the anion gap $\left(\mathrm{Na}^{+}-\left[\mathrm{Cl}^{-}+\mathrm{HCO}_{3}{ }^{-}\right]\right)$and serum osmolality $\left(2 \times \mathrm{Na}^{+}+\right.$Glucose/18+blood urea nitrogen $\left.[\mathrm{BUN}] / 3\right)$ may be useful in the differential diagnosis. Archival sample would be used to measure serum insulin, amino acids, ketone, hormones, and urine organic acids.

\section{Hypoglycemia}

\section{Definition and etiologies}

Any patient with a whole blood glucose concentration less than $50 \mathrm{mg} / \mathrm{dL}$ should be undertaken diagnostic and therapeutic procedures ${ }^{1)}$. Transient neonatal hypoglycemia is caused by enzyme immaturity or low substrates amount (prematurity, normal newborn), transient hyperinsulinism and persistent hyperinsulinism (small for gestational age, discordant twin, neonatal asphyxia). Persistent hypoglycemia is caused by hyperinsulinism (abnormal $\mathrm{K}^{+}$-ATP channel, abnormal glucokinase, abnormal glutamate dehydrogenase, acquired focal adenomatosis of pancreas islet, Beckwith-Wiedemann syndrome, insulin injection, sulfonylurea), counter-regulatory hormone deficiency (growth hormone [GH] deficiency, adrenocorticotropin hormone [ACTH] deficiency, Addison disease, epinephrine deficiency), glycogenolysis defects (glycogen storage disease $0,3,6,9$ ), gluconeogenesis defects (GSD 1a, 1b, galactosemia, fructose 1,6 diphosphatase deficiency, pyruvate carboxylase deficiency), lipolysis defect (propranolol) and fatty acid oxidation defects. But the most common cause of childhood hypoglycemia is ketotic hypoglycemia.

\section{Pathophysiology}

The utilization of glucose in most tissues is regulated by insulin and by the ability of the tissue to use ketones as an alternative energy source in the absence of glucose. Thus, disorders characterized by increased insulin secretion or by a relative inability to synthesize ketones (disorders of fatty acid oxidation) may lead to hypoglycemia caused by increased utilization and absence of ketones in blood and urine (nonketotic hypoglycemia)2).

The approximate glucose utilization rate of premature newborns is $10 \mathrm{mg} / \mathrm{kg} / \mathrm{min}$, term newborns $8 \mathrm{mg} / \mathrm{kg} / \mathrm{min}$, young children $6-8 \mathrm{mg} / \mathrm{kg} / \mathrm{min}$, older children and adolescents $4-6$ $\mathrm{mg} / \mathrm{kg} / \mathrm{min}$, adults $2-4 \mathrm{mg} / \mathrm{kg} / \mathrm{min}$. When glucose utilization begins to exceed production, the counterregulatory hormones (cortisol, GH, epinephrine, and glucagon) are secreted to prevent hypoglycemia. These hormones, acting individually or in concert, stimulate glycogenolysis and gluconeogenesis to restore and maintain normal serum glucose concentration. Deficiencies in the secretion of counterregulatory hormones or in the enzymes or substrates involved in either of these 2 processes can result in hypoglycemia, usually accompanied by excessive breakdown of triglycerides (TGs) and the production of ketones in the blood and urine $e^{2)}$. The CNS effects of hypoglycemia children beyond the newborn period are headache, irritability, confusion, fatigue, abnormal behavior, amnesia, altered level of consciousness, coma, and seizure. The adrenergic (epinephrine) effects are diaphoresis, cold extremities, tachycardia, pallor, tremor, anxiety, weakness, nausea, vomiting, and chest pain ${ }^{3)}$.

\section{Laboratory evaluation of hypoglycemia}

Initial sample should be checked for blood glucose, liver function tests, electrolytes, and bicarbonate from comprehensive metabolic profile and included urinalysis for presence or absence of ketones. Archival sample has to be measured serum insulin, ketones, GH, cortisol, c-peptide (for suspected exogenous hyperinsulinism), carnitine profile, amino acids, and toxins (ethanol, salicylates). Urine amino and organic acids and toxin screen are needed.

\section{Treatment}

Nonspecific therapy after initial and archival samples are obtained should go starting intravenous glucose $0.2 \mathrm{~g} / \mathrm{kg}$ ( $10 \%$ dextrose $2 \mathrm{~mL} / \mathrm{kg}$ ) quickly ${ }^{1}$. Ongoing therapy is required $6-8 \mathrm{mg} / \mathrm{kg} / \mathrm{min}$ glucose infusion rate for maintenance of euglycemia. Occasionally $10-20 \mathrm{mg} / \mathrm{kg} / \mathrm{min}$ of glucose infusion rate is needed via central venous line. Other nonspecific therapy are glucagon $0.03 \mathrm{mg} / \mathrm{kg}$ (subcutaneous or intramuscular injection) or Solu-Cortef 25 to $50 \mathrm{mg} / \mathrm{m}^{2}$ or 2 to $3 \mathrm{mg} / \mathrm{kg}$ intravenous injection ${ }^{1}$. Specific therapies of hyperinsulinism are long-acting somatostatin analogue $10 \mu \mathrm{g} / \mathrm{kg}$ every 6 to 12 hour subcutaneous injection and diazoxide $5-15 \mathrm{mg} / \mathrm{kg} /$ day (\#2) per oral, which may have several side effects.

\section{Hypocalcemia}

\section{Definition and etiologies}

Serum calcium concentration is maintained by dietary intake and absorption from the gut (mediated primarily by "active" vitamin D [1,25 dihydroxyvitamin D3]), and mobilization of calcium from the bone and across the renal tubules as a result of parathyroid hormone (PTH) secretion and action. PTH 
secretion is magnesium dependent, and its action is dependent on both magnesium and vitamin D. Deficiency in active vitamin $\mathrm{D}$ or magnesium, or in other causes of decreased secretion or action of PTH may result in hypocalcemia ${ }^{4}$. The definition of hypocalcemia in neonate is total serum calcium concentration less than $7.5 \mathrm{mg} / \mathrm{dL}$ (ionized $<3.8 \mathrm{mg} / \mathrm{dL}$ ) and in children is below $8.7 \mathrm{mg} / \mathrm{dL}$ (ionized $<4.6 \mathrm{mg} / \mathrm{dL})^{5}$.

\section{Pathophysiology}

The daily calcium requirement of the children and adolescence is 600 to $1,200 \mathrm{mg} /$ day. This is provided primarily in milk, milk products, and certain green vegetables. Vitamins D2 and D3 must be further metabolized sequentially in the liver (25-hydroxylase) and the kidney (1-a hydroxylase) to become their respective fully active derivatives, 1,25-dihydroxyvitamins D2 and D3, which are necessary to promote maximal absorption of calcium and phosphorus into the blood. The conversion of vitamin D2 or D3 to its active form is stimulated by PTH. Deficiencies of sunlight, milk or milk products, malabsorption of vitamin $\mathrm{D}$, failure to activate vitamin $\mathrm{D}$, or tissue unresponsiveness to vitamin $\mathrm{D}$ can predispose the child to hypocalcemia. Because vitamin D is the primary regulator of phosphorus homeostasis, hypocalcemia caused by insufficient vitamin D synthesis or action is usually accompanied by a decreased serum phosphorus concentration ${ }^{6,7)}$, in contrast to that caused by defects in PTH secretion or action. PTH is secreted by the parathyroid glands in response to hypocalcemia $^{7)}$. PTH mobilizes calcium and phosphorus from the bone. At kidney, calcium is retained, and mobilized phosphorus is actively excreted. Defects in the secretion or action of PTH (pseudohypoparathyroidism) lead to hypocalcemia and a relative inability to excrete phosphorus ${ }^{7}$. Hypocalcemia caused by one of these defects is accompanied by an increased serum phosphorus concentration. Defects in the calcium-sensing receptors in the parathyroid glands and the kidney may also result in abnormalities in the serum concentration of calcium ${ }^{5}$.

\section{History and physical examination}

Children who may be prone to hypocalcemia include those whose dietary problems predispose to vitamin D deficiency, premature infants (inadequate vitamin D storage), congenital heart defects (Di George syndrome), and hypoparathyroidism (autoimmune or removal of the parathyroid glands after surgery for thyroid carcinoma), pseudohypoparathyroidism, or chronic renal disease ${ }^{8)}$. Signs of hypocalcemia include lethargy, poor feeding and vomiting in infants, jitteriness, irritability, muscle spasm, laryngeal stridor, and tetany. Generalized seizures are common, so hypocalcemia should be ruled out in any child with an unexplained seizure ${ }^{5)}$. Carpopedal spasm is typical sign of hypocalcemia and facial muscle hyperirritability (Chvostek sign) may be elicited by tapping on the maxilla. Trousseau sign may be elicited in hypocalcemic patients by inflating a sphygmomanometer to $20 \mathrm{mmHg}$ above the systolic blood pressure.

\section{Laboratory evaluation}

The initial blood sample should be used to determine the total serum calcium, phosphorus, magnesium, sodium, potassium, and alkaline phosphatase levels. Hypocalcemia caused by disorders of vitamin D is usually characterized by decreased serum calcium and phosphorus levels with an elevated alkaline phosphatase level, whereas hypocalcemia caused by disorders of PTH secretion or action is accompanied by decreased serum calcium and alkaline phosphatase levels but increased serum phosphorus level $^{6}$. Archival blood sample should be sent for measurement of PTH and vitamin D metabolites. An archival urine sample may be sent for measurement of calcium and creatinine, to rule out a rare form of hypocalcemia termed "familial hypercalciuric hypocalcemia". The urinary calcium excretion (urinary calcium-creatinine ratio) is increased, in contrast to all other causes of hypocalcemia. Electrocardiography may be seen prolonged QT interval. If severe vitamin D deficient rickets may be evident, characteristic radiologic images show bowed appearance of the legs along with flaring at the wrists and knees ${ }^{7}$.

\section{Treatment}

Acute treatment consists of the intravenous (IV) administration of a dilute calcium solution, usually $10 \%$ calcium gluconate or lactate, $2 \mathrm{~mL} / \mathrm{kg}(20 \mathrm{mg} / \mathrm{kg})$ every 6 to 8 hours with cardiac monitoring and careful watching for extravasation of drug. Maintenance management usually consists of $50-75 \mathrm{mg} / \mathrm{kg}$ of elemental calcium daily as calcium carbonate or calcium lactate $^{5,7)}$. Pharmacologic doses of vitamin D3 for rickets are 150,000-600,000 U once intramuscular injection for severe vitamin D deficient rickets or 2,000-10,000 U/day (50-250 $\mu \mathrm{g} /$ day) per oral during 4-6 weeks ${ }^{5}$. 1,25-dihydroxyvitamin D3 20$60 \mathrm{ng} / \mathrm{kg} /$ day is required in the treatment of hypoparathyroidism and pseudohypoparathyroidism ${ }^{5}$. Magnesium deficiency of any etiology should be corrected before long-term treatment of hypocalcemia is undertaken, since it may be the primary defect, and the success of treatment of hypocalcemia is limited in cases of coexisting hypomagnesemia ${ }^{8)}$. Treatment consists of $50 \%$ magnesium sulfate $0.1 \mathrm{~mL} / \mathrm{kg}$ when serum magnesium concentration is below $1.5 \mathrm{mg} / \mathrm{dL}$ every 8 to 12 hours ${ }^{5,9)}$.

\section{Adrenal insufficiency}

\section{Etiologies}

The congenital causes of primary adrenal insufficiency are congenital adrenal hyperplasia $(\mathrm{CAH})$, autoimmune (Addison disease), adrenocortical hypoplasia congenita (AHC), adrenoleukodystrophy (ALD), Zellweger syndrome and 
Wolman syndrome. The acquired causes of primary adrenal insufficiency are adrenal hemorrhage, infections of adrenal gland and other infiltrative diseases. The secondary causes are hypothalamic disorders (empty sella syndrome, septo-optic dysplasia, craniopharyngioma, tumor and surgery/radiotherapy, infection), pituitary disorders (infections, congenital anomaly, tumor, and surgery/radiotherapy), and adrenal suppression from high-dose long-term steroid therapy ${ }^{10,11)}$. Children receiving pharmacological steroids for treatment of severe asthma, leukemia, organ transplantation or autoimmune diseases and children who are taking physiologic replacement steroids for central or primary hypoadrenalism are prone to adrenal crisis during acute febrile illness particularly vomiting (dehydration) $^{10-12)}$. Glucocorticoids administered for more than 10 to 14 days can suppress ACTH release for weeks and render the child susceptible to adrenal crisis $^{13-15)}$.

\section{Pathophysiology}

Hypovolemia and elevated serum potassium concentrations stimulate mineralocorticoid (aldosterone) release from the adrenal gland's zona glomerulosa under the stimulus of the renin-angiotensin II axis. Aldosterone acts on the distal renal tubule to effect sodium and water retention and enhanced hydrogen and potassium excretion into the urine. Thus, aldosterone serves a critical function by maintaining normal levels of total body sodium and water and protecting the body from hyperkalemia, dehydration, and shock ${ }^{13,14)}$. A striking feature of mineralocorticoid deficiency at any age, especially in the dehydrated infant, is polyuria. Corticotropin-releasing factor is released from the hypothalamus during times of stress or hypoglycemia and stimulates the release of ACTH from the pituitary gland. ACTH stimulates the adrenal gland's zona fasciculata to secrete the glucocorticoid (hydrocortisone), which is one of the body's major defenses against hypoglycemia and shock ${ }^{14)}$. Adrenal insufficiency results in a relative inability to maintain electrolyte balance, plasma volume, blood pressure, and blood glucose during times of stress, and may have a fatal outcome $^{15}$.

\section{History and physical examination}

The patients with adrenal insufficiency have weakness, anorexia, vomiting, weight loss, salt craving, and hyperpigmentation. They have tachycardia and hypotension and other signs of shock, which are pallor, poor peripheral perfusion, cold clammy skin, disturbed consciousness or even coma ${ }^{12}$. With dehydration, there may be decreased skin turgor, sunken eyes, and dry mucous membranes. Hyperpigmentation of gums, areolae, flexion creases reflects excessive secretion of ACTH. Ambiguous genitalia in girls with virilizing CAH may be present ${ }^{14}$.

\section{Laboratory evaluation}

The results of comprehensive metabolic profile from initial sample will show hyponatremia, metabolic acidosis (normal anion gap, increased serum chloride), hypoglycemia, and hypernatremia. If this pattern is found, blood should be drawn for level of plasma renin activity. The archival sample will be sent for serum cortisol and ACTH so that primary hypoadrenalism (decreased cortisol with elevated ACTH) may be differentiated from central causes (decreased cortisol without elevated ACTH). Neonates or infants suspected of having CAH, serum should be measured 17-hydroxyprogesterone or a complete adrenal metabolic profile, so that the specific enzymatic block may be identified ${ }^{14)}$. If hypopituitarism is suspected free $\mathrm{T} 4$ and GH should be determined ${ }^{11}$.

\section{Treatment}

Acute treatment of adrenal crisis is for rapid restoration of tissue perfusion. After an IV line is secured, a $20 \mathrm{~mL} / \mathrm{kg}$ bolus of normal saline ( $5 \%$ dextrose $/ 0.9 \% \mathrm{NaCl}$ ) is given over a period of an hour. If significant hypoglycemia is present, a glucose of bolus $0.2 \mathrm{~g} / \mathrm{kg}(2 \mathrm{~mL} / \mathrm{kg}$ of $10 \%$ dextrose) is given to restore euglycemia. Stress doses of glucocorticoid, Solu-Cortef should be loading $\left(25-50 \mathrm{mg} / \mathrm{m}^{2}\right.$ or $2-3 \mathrm{mg} / \mathrm{kg}$ ). Hydrocortisone has a desirable mineralocorticoid effect as well as its glucocorticoid effect (20-35 mg Solu-Cortef has the mineralocorticoid effect of 0.1-mg fludrocortisone [Florinef]), whereas methylprednisolone (Solu-Medrol) and dexamethasone have only a glucocorticoid effect and are not suitable therapies in this case ${ }^{13)}$.

Ongoing IV steroid therapy consists of Solu-Cortef given as a total daily dose of $25-50 \mathrm{mg} / \mathrm{m}^{2}$ or $2-3 \mathrm{mg} / \mathrm{kg}$ in divided doses every 6 hours. Hyperkalemia higher than $6 \mathrm{mEq} / \mathrm{L}$ can induce fatal cardiac arrythmias and requires aggressive therapy with sodium bicarbonate, 1 to $2 \mathrm{mEq} / \mathrm{kg}$ IV over 10 to 15 minutes; calcium gluconate, 50 to $100 \mathrm{mg} / \mathrm{kg}$ (maximum dose, $1 \mathrm{~g}$ ) by slow (5-10 minutes) IV drip; or IV glucose, $500 \mathrm{mg} / \mathrm{kg}(2 \mathrm{~mL} /$ $\mathrm{kg} 25 \%$ glucose solution) plus insulin, 0.1 units $/ \mathrm{kg}$. A potassiumbinding resin, sodium polystyrene sulfonate (Kayexalate), $1 \mathrm{~g} / \mathrm{kg}$ rectally or orally, should be given if tolerated ${ }^{13)}$.

\section{Metabolic acidosis}

\section{Etiologies}

The metabolic acidosis can be resulting from (1) a loss of base (bicarbonate) from the body, either through the kidneys or the gastrointestinal tract (normal anion gap), or from (2) abnormal accumulation of acid through overproduction (diabetic ketoacidosis [DKA], lactic acidosis, or inborn errors of metabolism), (3) under excretion (type 1 [distal] renal tubular acidosis or chronic renal failure) ${ }^{16)}$, or toxic ingestion (increased anion gap $)^{17}$. 


\section{Pathophysiology}

Acidosis that ultimately exceeds the body's compensatory buffering mechanisms leads to an increase in extracellular fluid $\mathrm{H}^{+}$concentration so that the $\mathrm{pH}$ of the blood is reduced below 7.35. This state is referred to as "academia", and its presence warrants prompt treatment to prevent severe alterations in extracellular and intracellular $\mathrm{pH}$ that might be incompatible with life. To maintain electrical neutrality in the body, the total positively charged ions (cations) must always equal the total negatively charged ions (anions). Normally, $\mathrm{Na}^{+}$accounts for more than $90 \%$ of the extracellular cations, whereas $\mathrm{Cl}^{-}$ and $\mathrm{HCO}_{3}{ }^{-}$constitute approximately $85 \%$ of the anions. The "anion gap" is the calculated difference between the majority of measured cations $\left(\mathrm{Na}^{+}\right)$and the majority of measured anions (the sum of $\mathrm{Cl}^{-}$and $\left.\mathrm{HCO}_{3}^{-}\right)^{17)}$.

1) Normal anion gap ("hyperchloremic") metabolic acidosis

(1) Diarrhea or small bowel drainage can lead to excessive loss of $\mathrm{Na}^{+}$and $\mathrm{HCO}_{3}{ }^{-}$from the gastrointestinal tract with the subsequent development of metabolic acidosis. Since sodium and bicarbonate are lost together, and hyperchloremia develops, the calculated anion gap is normal. Loss of sodium bicarbonate through the kidneys may also occur, either caused (2) by an altered renal bicarbonate reabsorption threshold in type 2 (proximal) renal tubular acidosis, early in generalized renal tubular dysfunction, or caused (3) by mineralocorticoid deficiency (e.g., Addison disease or some type of the $\mathrm{CAH})^{17,18}$.

\section{2) Increased anion gap metabolic acidosis}

The endogenous production or ingestion of acid load or a failure of the kidneys to excrete sufficient $\mathrm{H}^{+}$daily results in metabolic acidosis. Those may progress to acidemia if the ability of the body's other compensatory mechanisms to neutralize this condition is exceeded. This is accompanied by decreased serum bicarbonate levels because of the increased demands on the body's buffering capacity by excessive $\mathrm{H}^{+}$ accumulation, and the calculated anion gap is increased. In the neonatal period, (1) inborn errors of metabolism that lead to accumulation defective substrates of amino/organic acids result in increased anion gap metabolic acidosis. (2) The ingestion of toxins that are acid precursors and that may also disrupt normal metabolism so that organic acids accumulate. Examples of these are acetylsalicylic acid, methanol, ethylene glycol (antifreeze), and they may also result in a measured serum osmolality much greater than calculated ("osmole gap"). The inborn errors of carbohydrate metabolism that lead to fasting hypoglycemia may also result in increased anion gap metabolic acidosis because of the excessive production of ketone bodies (acetoacetate and beta-hydroxybutyrate) that are derived from the breakdown of fatty acids being used as an alternate energy source. (3) DKA is usually occurred by absolute/relative insulin deficiency, either caused by noncompliance with insulin in children with known type 1 diabetes mellitus (DM) or by an excess secretion of the counterregulatory hormones (cortisol, epinephrine, GH, and glucagon) during stress (infection, trauma, and surgery). Hyperglycemia and relative hyperkalemia are manifest early in the course of DKA. The increased urine output and hyperkalemia result in extracellular dehydration as well as electrolyte $\left(\mathrm{Na}^{+}\right.$and $\left.\mathrm{HCO}_{3}^{-}\right)$loss, resulting in an initial normal anion gap (hyperchloremic) metabolic acidosis. As insulin deficiency continues in the presence of excessive counterregulatory hormone secretion, accelerated breakdown of glycogen and protein occurs and gluconeogenesis increases, with a resulting augmented glucose production by the liver and rapidly worsening hyperglycemia ${ }^{19}$. The cellular inability to use blood glucose, excessive cortisol and epinephrine secretion and insufficient insulin, stimulates the breakdown of TGs to free fatty acids. These overwhelm the ability of the liver to metabolize them for energy, and result in a rapidly increasing accumulation of acetoacetate and beta-hydroxybutyrate, the "ketone bodies". The ketone bodies are moderately strong acids, which are ionized at physiologic $\mathrm{pH}$ and release hydrogen ions that produce an increased anion gap metabolic acidosis.

\section{History and physical examination}

In patients with new or established type $1 \mathrm{DM}$, there is often a history of recent emotional stress or infection that can be a precipitating factor in the development of DKA. In many cases, no particular precipitating event can be identified. Known metabolic disease in the family is a valuable clue. Symptoms of hypoglycemia during fasting or after specific foods (e.g., fruit [fructose containing]) can be diagnostic of an inborn error of metabolism, history of unusual urine odor. These include persistent vomiting and tachypnea resulting from the body's attempt to compensate for the acidosis by ridding itself of the excess acid through the gastrointestinal tract or lungs. Changes caused by acidosis in the peripheral and central vasculature give rise to warm, flushed skin, abdominal pain, and headache. If the abdominal pain and vomiting in a child with DKA do not resolve as the acidosis is corrected, then an evaluation of the "acute abdomen" should be undertaken. Acidemia and hyperosmolality also result in CNS dysfunction, manifested as altered levels of consciousness progressing to coma, seizures, and even death if they are not treated in a timely manner. In the patient with DKA, variable degrees of dehydration, from mild to severe, may be present and will be manifest as lack of normal skin turgor, sunken eyes, tachycardia, and hypotension. In patient with severe acidosis $(\mathrm{pH}<7.0)$, suppression of cardiac and pulmonary function may occur, and ventilatory assistance may be necessary. The patient in DKA may have a characteristic "fruity" odor to the breath because of exhaling the ketone body acetoacetate ${ }^{19)}$.

\section{Laboratory tests}

A comprehensive metabolic profile in the initial blood 
sample will reveal the decrease in serum bicarbonate that defines the acidosis. The electrolyte/BUN/creatinine portion of the profile is a reasonable guide to renal function and in DKA case, hyperglycemia is present. Note that in the presence of metabolic acidosis, intracellular potassium is displaced into the extracellular space. Thus, midnormal concentration of $4.2 \mathrm{mEq} /$ $\mathrm{L}$ of $\mathrm{K}^{+}$would not be normal at $\mathrm{pH}$ less than 7.3 and indicate potassium deficiency. If the measured serum osmolality is more than 10 to $15 \mathrm{mOsm} / \mathrm{kg}$ greater than the calculated osmolality, a significant "osmole gap" exists, and suggests the presence of an unmeasured osmole (e.g., methanol or ethylene glycol). Since DKA is the most common cause of significant metabolic acidosis beyond infancy, obtaining serum ketones is important. Serum calcium, magnesium, phosphate, and $\mathrm{HbAlc}$ concentrations should be measured ${ }^{20)}$. A complete urinalysis is also helpful in assessing renal function and in documenting ketonuria in DKA. Occasionally, a patient has severe hyperglycemia $(>1,000$ $\mathrm{mg} / \mathrm{dL}$ ) in the absence of metabolic acidosis. This is often accompanied by a significantly reduced level of consciousness as a result of extracellular hyperosmolality, and has been termed "nonketotic hyperglycemic coma (NKHC) ${ }^{120)}$

The archival samples of blood and urine may be sent for toxin screens, especially if a significant serum osmole gap is present or if the history suggests ingestion of a toxin. Infants with metabolic acidosis may have an inborn error of metabolism, and determination of serum amino and urine amino and organic acids are useful diagnostically. In patient with sepsis or hypoxia/ hypovolemia, measurements of serum lactic and pyruvic acid concentrations are useful. In this case, both acids may be elevated, but the lactate-to-pyruvate ratio will be increased (>10:1), because of the patient's relative anaerobic metabolic state. In infants with primary (inborn) lactic acidosis, both lactic and pyruvic acid concentrations are elevated in the serum, but the ratio is usually normal.

\section{Treatment}

\section{1) General}

The initial approach to the child with metabolic acidosis involves maintenance of normal extracellular volume and correction of dehydration. This should be begun with an IV infusion of $5 \%$ dextrose in $0.9 \% \mathrm{NaCl}$ with potassium, $20 \mathrm{mEq} /$ $\mathrm{L}$ or greater, depending on the potassium deficit. Maintaining IV fluid volumes may be calculated from an estimation of the degree of existing dehydration and ongoing fluid losses in an individual patient. Alkalai therapy in the form of sodium bicarbonate should be used sparingly. Except for some of the inborn errors of metabolism, metabolic acidosis will improve with fluid therapy alone as tissue perfusion improves and cellular metabolism normalizes. Ketones and lactic acid may be endogenously metabolized to bicarbonate. Thus, bicarbonate therapy may be unnecessary and may actually be harmful. The use of bicarbonate during the treatment of DKA poses a significantly increased risk of cerebral edema. If the DKA patient's serum $\mathrm{pH}$ is less than 6.9 , the deleterious effects of severe acidosis on cardiopulmonary function may warrant limited bicarbonate therapy. Sodium bicarbonate, 1 to $2 \mathrm{mEq} /$ $\mathrm{kg}$, may be added to the IV fluids over approximately 60 minutes in these circumstances ${ }^{20,211}$.

\section{2) DKA}

Initial fluid therapy should be begun with an IV infusion of $0.9 \% \mathrm{NaCl} 10$ to $20 \mathrm{~mL} / \mathrm{kg}$ body weight given during the first hour followed by continuous insulin infusion $0.1 \mathrm{U} / \mathrm{kg} / \mathrm{hr}$. Next hour fluid therapy consist of $0.45 \% \mathrm{NaCl}$ plus potassium 40 $\mathrm{mEq} / \mathrm{L}\left(50 \% \mathrm{KCl}+50 \% \mathrm{KPO}_{4}\right)$ or depending on the estimate of the patient's potassium deficit. Dextrose may be omitted from the initial IV fluids in a patient with DKA only if the initial serum glucose concentration is greater than $300 \mathrm{mg} /$ dL. But $5 \%$ dextrose should be added to the IV fluids when the serum glucose concentration reaches $250-300 \mathrm{mg} / \mathrm{dL}$ to prevent hypoglycemia and to help minimize the rate of fall in extracellular osmolality. Although the average decrease in serum glucose concentration on the standard IV "insulin plus fluid" regimen is $75 \mathrm{mg} / \mathrm{dL}$ per hour, there is considerable variation between patients, and hourly monitoring of serum glucose is warranted. On occasion, it is necessary to use $10 \%$ dextrose in the IV fluids to maintain serum glucose concentrations of 150 to $250 \mathrm{mg} / \mathrm{dL}$. Maintenance fluids should be administered evenly over each 24 -hour period, but estimated fluid deficits should be replaced cautiously, over at least 36 hours, with longer times if the initial serum osmolality is greater than $320 \mathrm{mOsm} /$ $\mathrm{kg}$. Potassium and phosphorus deficits are difficult to estimate based on their serum concentrations, but the addition of $20 \mathrm{mEq}$ $\mathrm{KCl}$ plus $20 \mathrm{mEq} \mathrm{KHPO}_{4}$ per liter of IV fluids usually suffices to replace these deficits. Hourly monitoring of serum potassium is warranted for the first few hours of treatment, and every 2 hours thereafter. The prevention of cerebral edema is important during the course of treatment. Since the patient's brain is in equilibrium with the hyperosmolar extracellular space in DKA, it is prudent to avoid rapid changes in extracellular osmolality so that fluid movement into the hyperosmolar CNS does not occur. Since the serum sodium concentration is decreased because of the osmotic effect of hyperglycemia in DKA, it should increase gradually as the serum glucose concentration decreases during insulin therapy. Monitoring the serum sodium concentration hourly during the first few hours of therapy is therefore initial to ensure that this occurs and that rapid changes in serum osmolality do not occur. The insulin infusion should be begun as soon as the diagnosis is made, irrespective of the patient's serum glucose, since the degree of acidemia may not correlate with serum glucose concentration. A solution of 1 unit/5 mL can be made by adding 50 units rapid acting insulin to $250 \mathrm{~mL}$ $0.9 \% \mathrm{NaCl}$ and used for this purpose. In patients whose serum glucose concentration is less than $300 \mathrm{mg} / \mathrm{dL}$, dextrose should be added to the initial IV fluids. The insulin infusion is usually continued until the serum bicarbonate concentration is greater than $15 \mathrm{mEq} / \mathrm{L}$, the venous $\mathrm{pH}$ is greater than 7.30 , or both, and at that time, a regimen of subcutaneous insulin is begun ${ }^{21)}$. 
In most cases, venous blood suffices to determine the patient's acid-base balance, and arterial blood would only be required to assess the state of oxygenation in the obtunded patient. In NKHC, the patient's serum osmolality is usually greater than $320 \mathrm{mOsm} / \mathrm{kg}$, and fluid deficits should be replaced over 48 hours. In addition, an initial insulin infusion rate of 0.05 units/ $\mathrm{kg}$ per hour in $0.9 \% \mathrm{NaCl}$ may be used to further minimize the chances of rapid decreases in serum osmolality ${ }^{22}$.

\section{3) Cerebral edema}

Cerebral edema may already be present when the patient arrives in the emergency department. This usually results from a lack of appropriate treatment caused by delays in the diagnosis of DKA, and accounts for half of the $2 \%$ mortality rate seen in childhood DKA. A secondary form of cerebral edema presents within hours of the onset of treatment in DKA patient and is heralded by a change in level of consciousness or a complaint of headache. This is probably associated with rapid fluid shifts into the CNS when extracellular osmolality is reduced too quickly or when bicarbonate is used inappropriately. The prevention of this form of cerebral edema may be accomplished by avoiding the overuse of fluids (keeping the initial fluid bolus $<20 \mathrm{~mL} / \mathrm{kg}$, keeping total fluids $<50 \mathrm{~mL} / \mathrm{kg}$ over the first 4 hours or $<4 \mathrm{~L} /$ $\mathrm{m} 2$ over the first 24 hours of treatment and by replacing deficits over 36 to 48 hours $^{22,23)}$. If these precautions have been followed and the patient's mental status is worsening, IV mannitol $(1 \mathrm{~g} / \mathrm{kg}$ over 20 minutes) may be given ${ }^{19)}$.

\section{Conclusions}

Because the symptoms and signs of the endocrine metabolic emergencies of the pediatric patients are nonspecific, a suspicion and collection of the initial sample should be preceded prior to starting therapy. Also archival sample should be obtained simultaneously and be held in the laboratory for future measurement. In addition to hypoglycemia, hypocalcemia, adrenal insufficiency, and metabolic acidosis including diabetic ketoacidosis, these samples will be so useful for diagnosis and treatment of other endocrine metabolic disorders in Emergency Department.

\section{Conflict of interest}

No potential conflict of interest relevant to this article was reported.

\section{References}

1. The Korean Society of Pediatric Endocrinology, editor. Pediatric endocrinology. 3rd ed. Seoul: Koonja Co., 2014. Hypoglycemia; p. 515-26.

2. Lteif AN, Schwenk WF. Hypoglycemia in infants and children. Endocrinol Metab Clin North Am 1999;28:619-
46.

3. Cornblath M, Hawdon JM, Williams AF, Aynsley-Green A, Ward-Platt MP, Schwartz R, et al. Controversies regarding definition of neonatal hypoglycemia: suggested operational thresholds. Pediatrics 2000;105:1141-5.

4. Shaul PW, Mimouni F, Tsang RC, Specker BL. The role of magnesium in neonatal calcium homeostasis: effects of magnesium infusion on calciotropic hormones and calcium. Pediatr Res 1987;22:319-23.

5. The Korean Society of Pediatric Endocrinology, editor. Pediatric endocrinology. 3rd ed. Seoul: Koonja Co., 2014. Hypocalcemia; p. 257-94.

6. Misra M, Pacaud D, Petryk A, Collett-Solberg PF, Kappy M; Drug and Therapeutics Committee of the Lawson Wilkins Pediatric Endocrine Society. Vitamin D deficiency in children and its management: review of current knowledge and recommendations. Pediatrics 2008;122:398-417.

7. Shaw N. A practical approach to hypocalcaemia in children. Endocr Dev 2009;16:73-92.

8. Song JY, Shin YL, Yoo HW. Clinical characteristics of symptomatic hypocalcemic infants. J Korean Soc Pediatr Endocrinol 2002;7:95-104.

9. Root AW, Diamond FB Jr. Disorders of mineral homeostasis in the newborn, infant, child, and adolescent. In: Sperling MA, editor. Pediatric endocrinology. 3rd ed. Philadelphia: Elsevier Saunders Co., 2008:686-769.

10. Bornstein SR. Predisposing factors for adrenal insufficiency. N Engl J Med 2009;360:2328-39.

11. The Korean Society of Pediatric Endocrinology, editor. Pediatric endocrinology. 3rd ed. Seoul: Koonja Co., 2014. Adrenocortical insufficiency; p. 325-57.

12. Arlt W, Allolio B. Adrenal insufficiency. Lancet 2003;361: 1881-93.

13. Miller WL, Achermann JC, Fluck CE. The adrenal cortex and its disorders. In: Sperling MA, editor. Pediatric endocrinology. 3rd ed. Philadelphia: Elsevier Saunders Co., 2008:444-511.

14. Speiser PW, White PC. Congenital adrenal hyperplasia. N Engl J Med 2003;349:776-88.

15. Langer M, Modi BP, Agus M. Adrenal insufficiency in the critically ill neonate and child. Curr Opin Pediatr 2006; 18:448-53.

16. Rothstein M, Obialo C, Hruska KA. Renal tubular acidosis. Endocrinol Metab Clin North Am 1990;19:869-87.

17. Lim S. Metabolic acidosis. Acta Med Indones 2007;39:14550.

18. Lorenz JM, Kleinman LI, Markarian K, Oliver M, Fernandez J. Serum anion gap in the differential diagnosis of metabolic acidosis in critically ill newborns. J Pediatr 1999;135:751-5.

19. The Korean Society of Pediatric Endocrinology, editor. Pediatric endocrinology. 3rd ed. Seoul: Koonja Co., 2014. Diabetic ketoacidosis; p. 607-15.

20. Glaser N, Barnett P, McCaslin I, Nelson D, Trainor J, Louie J, et al. Risk factors for cerebral edema in children with 
diabetic ketoacidosis. The Pediatric Emergency Medicine Collaborative Research Committee of the American Academy of Pediatrics. N Engl J Med 2001;344:264-9.

21. Wolfsdorf J, Craig ME, Daneman D, Dunger D, Edge J, Lee WR, et al. Diabetic ketoacidosis. Pediatr Diabetes 2007;8:28-43.

22. Wolfsdorf J, Glaser N, Sperling MA; American Diabetes
Association. Diabetic ketoacidosis in infants, children, and adolescents: A consensus statement from the American Diabetes Association. Diabetes Care 2006;29:1150-9.

23. Resenbloom AL. Therapeutic controversy: prevention and treatment of diabetes in children. Cerebral edema in diabetic ketoacidosis. J Clin Endocrinol Metab 2000;85: 507-8. 